\title{
Numerical Modeling of Heat Affected Zone Cracking Tendency during Laser and Hybrid Laser-Arc Welding Processes
}

\author{
Zhiguo Gao \\ Department of Mechanical \& Manufacturing Engineering \\ University of Manitoba, Winnipeg R3T 5V6, Manitoba, Canada \\ E-mail: gzgshang@gmail.com \\ O. A. Ojo \\ Department of Mechanical \& Manufacturing Engineering \\ University of Manitoba, Winnipeg R3T 5V6, Manitoba, Canada \\ Tel: 1-204-474-7972 E-mail: ojo@cc.umanitoba.ca
}

Received: December 6, $2011 \quad$ Accepted: December 19, $2011 \quad$ Published: Apri1 1, 2012
doi:10.5539/jmsr.v1n2p42

The research is funded by the NSERC of Canada and the Standard Aero Ltd., Winnipeg, Canada.

\begin{abstract}
A two-dimensional thermal elasto-plastic numerical model is developed by finite element method to analyze and compare the mechanical driving factor for heat affected zone (HAZ) liquation cracking during laser welding and hybrid laser-arc welding techniques. Calculations of transient temperatures and cooling rates are used in conjunction with solidification theory to analyze weld pool characteristics during weld-metal solidification. The model is successfully verified by comparing calculated and experimental weld bead geometry and secondary dendrite arm spacing within the weld solidification microstructure. Computational analyses by the model provide valuable insights both into the influence of welding parameters on thermally induced strain rate gradient, which influences cracking, and possible reduced HAZ cracking tendency with the application of hybrid laser-arc welding compared to ordinary laser beam welding.
\end{abstract}

Keywords: Laser welding, Hybrid laser-arc welding, Joining

\section{Introduction}

Precipitation strengthened nickel-base superalloys are extensively used in hot sections of aero engines and land-based power generation gas turbines, due to their excellent elevated temperature mechanical properties and resistance to hot corrosion. The harsh gas turbine service environment coupled with operating stress conditions, however, often cause these materials to suffer various forms of damage in service, such as, thermo-mechanical fatigue cracking and surface erosion degradation. Damaged components reduce structural integrity and operating efficiency. In most cases, it is more economically viable to carry out repair to return the degraded parts to serviceable condition rather than total replacement, due to higher manufacturing cost and longer delivery time of new components. Welding is a desirable economical and versatile technique for joining nickel-base superalloys both during fabrication as well as to repair damaged sections. Among various welding techniques, laser welding is an attractive welding process for joining superalloys due to its technological advantages, including low heat input that minimizes part distortion during joining. In the recent years, advancement in joining technology has resulted in the development of hybrid laser-arc welding, which has several advantages over conventional laser welding. The synergistic effect, produced by interaction of laser and arc produces extra energy for welding at increased travel speed and deeper weld penetration, along with better gap bridging capability and improved process stability and efficiency (Gao, et al., 2009; Ribic, et al., 2009; Claus \& Flemming, et al., 2010). A problem that is often encountered during laser welding of nickel-base superalloys is heat affected zone (HAZ) cracking (Egbewande, et al., 2010; Liu, et al., 2011; Hong, et al., 2008). The HAZ cracking generally occurs 
along the grain boundaries and it is usually associated with the formation of intergranular liquid film during welding. The inability of the liquid film to accommodate thermally induced stresses experienced during weld cooling results in grain boundary micro-fissuring through decohesion along one of the solid-liquid interfaces on the grain boundary. The rate of deformation of the HAZ while it contains solid grains and intergranular liquid is a major mechanical factor that drives cracking occurrence. Even though hybrid laser-arc welding offers a number of advantages over conventional welding, application of the joining technique to nickel-base superalloys in lieu of laser welding requires adequate understanding and comparison of cracking tendency during the two joining methods. This is the motivation for this research, which was initiated with the primary objective to develop a numerical model to analyze and compare thermally-induced strain rate and its dependency on process parameters during laser and hybrid laser-arc welding techniques. The model description and the results of the study are reported and discussed in this paper.

\section{Model Description}

In consideration of tractable object symmetry, a two dimensional model with $6 \mathrm{~mm} \times 19 \mathrm{~mm}$ dimensions, which includes the weld-metal and the base-metal is adopted in this study. The model elements are substantially square-shaped with $50 \mu \mathrm{m}$ size near the weld-metal fusion boundary line to adequately simulate the melting and solidification processes during welding. A non-uniform mesh is used along the transverse direction of the work-piece. The left side of work-piece is restrained in the $\mathrm{x}$ and $\mathrm{y}$ directions with symmetry boundary condition, while the right edge is constrained in the $\mathrm{x}$ direction. A sequential thermal-mechanical finite element analysis is performed by using the ANSYS 13 code. Specifically, two dimensional (2-D) thermal solid plane55 is used to simulate the temperature field and 2-D structure element plane 42 is then used to calculate the stress-strain field. The base material and the filler material that are used in the model have the same physical and mechanical properties. Microstructural modifications in the HAZ, such as, changes in texture, recrystallization and grain growth, which may be negligible in cast materials, are not considered in the model. Temperature dependent heat conductivity, specific heat of thermal expansion and density, as well as, uniform absorption and release of latent heat of fusion are incorporated into the model. The Young's modulus and Poisson's ratio are used for the linear elasticity calculation in the elastic region, while the material follows von Mises yield criteria in the plastic region. Bilinear Kinematic Hardening rule is adopted for the temperature dependence of yield strength and tangent modulus. All the material properties used in the model are presented in Figure 1 (Luo, et al., 2002; Dye, et al., 2001; Bonifaz, et al., 2009; Pottlacher, et al., 2002).

The model utilizes sequential transient heating of the work-piece by laser and gas metal arc (GMA) heat sources. The laser beam is represented by the Rotary-Gauss heat energy distribution source, q, which is suitable for nail-shaped molten pool with large depth to width ratio along the work-piece thickness (Wu, et al., 2004) that is;

$$
\begin{gathered}
q(x, y, z)=q(0,0) \exp \left[\frac{-3 c_{s}}{\log \left(\frac{H}{z}\right)}\left(x^{2}+y^{2}\right)\right] \\
q(0,0)=\frac{3 c_{s} Q \eta_{l}}{\pi H\left(1-\frac{1}{e^{3}}\right)} \\
c_{s}=\frac{3}{R_{0}^{2}}
\end{gathered}
$$

where $\mathrm{H}$ is the height of heat source, $\mathrm{Q}$ is the power of laser beam, $\mathrm{R}_{0}$ is the radius of heat source, and $\eta_{1}$ is heat transfer efficiency of the laser. The efficiency of the laser beam heat transfer during welding is assumed to be 0.21 (Hee, et al., 2010; Cho, et al., 2010). The distribution of the GMA heat energy is represented by Gaussian flux over the work-piece surface, i.e.;

$$
q(x, y)=\frac{V I \eta_{a}}{2 \pi \delta^{2}} \exp \left(-\frac{x^{2}+y^{2}}{2 \delta^{2}}\right)
$$

where $\mathrm{V}$ and I are the voltage and current of the arc, respectively, and $\delta$ is the distribution parameter of the heat flux, which is taken to be $2.5 \mathrm{~mm}$ (Tsai \& Eagar, 1985). $\eta_{\mathrm{a}}$ is the heat transfer efficiency of GMA and it is 
assumed to be 0.85 (Hee, et al., 2010). Heat exchange between the welded material and its surrounding through convection and radiation is taken into account by heat transfer coefficient $h_{c}$, through which both the temperature dependence of convection and radiation are estimated by using the equation (Goldak, et al., 1984):

$$
h_{c}=0.00241 \varepsilon T^{1.61}
$$

where $\varepsilon$ is the emissivity and $\mathrm{T}$ is the temperature.

Assuming that mass is conserved during single pass welding process, the transverse cross-sectional area of the weld is given by (Ushio \& $\mathrm{Wu}, 1997)$ :

$$
A=\frac{S \pi d^{2}}{4 U_{0}}
$$

where $\mathrm{A}$ is the area of weld reinforcement, $\mathrm{S}$ is wire feed rate, $\mathrm{d}$ is the wire diameter and $\mathrm{U}_{0}$ is the welding speed. The dendrites, which are formed during weld pool solidification, are assumed to grow in a direction perpendicular to the solidification growth front. Local growth velocity of dendrite along the solidification front, as a function of undercooling, is represented by the following equation (Hunziker, 2000):

$$
v_{\text {kin }}\{\Delta T\}=a \Delta T^{n}
$$

where $n=3.05, a=1.2754 \times 10^{-7} \mathrm{~ms}^{-1} \mathrm{~K}^{-3.05}$. The under-cooled liquid region is the defined as the region between the dendrite growth front and liquidus temperature.

The total strain used in the model is given by:

$$
\{\varepsilon\}=\left\{\varepsilon^{e l}\right\}+\left\{\varepsilon^{t h}\right\}+\left\{\varepsilon^{p l}\right\}
$$

where $\varepsilon^{\mathrm{el}}$ is elastic strain vector, $\varepsilon^{\text {th }}$ is thermal strain vector and $\varepsilon^{\mathrm{pl}}$ is plastic strain vector.

The incremental forms of stress-strain relation are described by (Kong \& Kovacevic, 2010; ANSYS; Chang \& Lee, 2009; Akbari \& Sattari-Far, 2009):

$$
\begin{gathered}
{[d \delta]=\left[D^{e p}\right]\{d \varepsilon\}-\left[D^{t h}\right] d T} \\
{\left[D^{e p}\right]=\left[D^{e}\right]+\left[D^{p}\right]}
\end{gathered}
$$

where $d \delta$ is the stress increment, $d \varepsilon$ is the strain increment, $\left[D^{\mathrm{e}}\right]$ is the elastic stiffness matrix, $\left[\mathrm{D}^{\mathrm{p}}\right]$ is the plastic stiffness matrix, $\left[\mathrm{D}^{\text {th }}\right]$ is the thermal stiffness matrix and $\mathrm{dT}$ is the temperature increment.

\section{Model Verification}

A primary criterion for a model to be suitable for studying thermally induced strain and its variation with time and distance along the weld profile, which is necessary in understanding the driving factor for HAZ cracking, is the ability of the model to reliably predict weld geometry. Therefore, verification of the model developed in this work was performed firstly by comparing calculated weld geometry by the model with experimental weld geometry. Figure 2 shows a comparison between the model predicted laser weld geometry and experimental laser weld geometry at a laser power of $4 \mathrm{~kW}$ and a welding speed of $3 \mathrm{~m} / \mathrm{min}$. As can be seen from the figure, a good correlation exists between the numerically computed and experimental results

Weld cooling rate is known to have a significant effect on the size of the spacing between secondary dendrites that form within the weld microstructure during solidification. The secondary dendrite arm spacing, $\lambda \mathrm{s}$, has been related to the cooling rate, $\Theta$, through the equation (Quested \& McLean, 1980)

$$
\lambda \mathrm{s}=\mathrm{k}_{\mathrm{s}} \Theta^{\mathrm{n}}
$$

where $\mathrm{k}_{\mathrm{s}}$ and $\mathrm{n}$ are constants. The solidification growth rate, $\mathrm{R}$, and the temperature gradient ahead of the solidification front, $\mathrm{G}$, were used in the model to compute the cooling rates ( $\mathrm{G} \times \mathrm{R})$, which were then used to calculate the secondary dendrite arm spacing along the weld fusion boundary. Figure 3 shows variation of calculated and experimental $\lambda \mathrm{s}$ along the weld fusion boundary. A similar trend in the variation of $\lambda \mathrm{s}$ along the fusion boundary, starting from the weld top surface to the root of the weld, can be observed for the calculated 
and experimental values. These, thus, indicate the reliability of the model for reasonably computing the weld geometry and cooling rate, which are vital in determining the requisite strain rate at different weld locations for accessing the HAZ cracking tendency.

\section{Results and Discussion}

The welding parameters used in the numerical simulation study are listed in Table 1. A fundamental factor that affects weld characteristics is the heat input involved during welding. In its basic form, heat input, $\mathrm{H}_{\mathrm{I}}$, is dependent on the power of the welding heat source power, $\mathrm{P}$, and welding speed, $\mathrm{V}$, through the equation;

$$
\mathrm{H}_{\mathrm{I}}=\mathrm{kP} / \mathrm{V}
$$

where $\mathrm{k}$ is a constant. Accordingly, welding heat input can be varied by either changing power or welding speed. In this study, both power and welding speed were varied, exclusive of each other, to analyze the effects of heat input on weld characteristics during laser and hybrid laser-arc welding techniques. Figures $4 \mathrm{a}, 4 \mathrm{~b}, 4 \mathrm{c} \& 4 \mathrm{c}$ show numerically calculated weld shape profiles produced by varying welding speed at a constant power and varying power at a constant speed during laser welding and hybrid laser-arc welding, respectively. The results obtained by changing the welding speed and power are consistent, in that, they show similar trend in the effect of heat input on weld geometry. Increase in the welding speed reduces weld surface width and weld depth, while opposite effects are produced with increase in power. The model calculated results are in agreement with reported experimentally observed trends in the literature (Chen, et al., 2006; Ribic, et al., 2008a; 2008b; Rai, et al., 2007).

The metallurgical cause of weld HAZ cracking in nickel-base superalloys is generally known to be the formation of liquid film along the HAZ grain boundary regions during welding (Nishimoto, et al., 2002). The intergranular liquid degrades the ability of the material to accommodate thermally generated strains during weld cooling. The material recovers its capability to accommodate thermal strains only after the intergranular liquid had completely solidified at a lower temperature, which is often referred to as ductility recovery temperature (DRT) (Lin, et al., 1992). The temperature range between the on-heating peak temperature, $T_{p}$, and the DRT, is usually referred to as brittle temperature range (BTR) (Lin, et al., 1992). Cracking occurs when significant amount of thermal strains are generated within the BTR during weld cooling. The rates at which strains develop at different weld locations, thus, become important in evaluating propensity to HAZ liquation cracking. Thermally induced strain rate during weld cooling is influenced by welding process parameters.

The numerical model developed in the work was used to calculate the strain rates generated at various locations along the weld fusion boundary and how these values are influenced by welding speed and power. Figures $5 \mathrm{a}, 5 \mathrm{~b}$, $6 \mathrm{a}$ and $6 \mathrm{~b}$ show numerically calculated variation of strain rate along the weld profile for different values of welding speed and power, during laser welding and hybrid laser-arc welding, respectively. The abscissa shows the distance from the weld top surface to the root of the weld, along the weld fusion boundary. The right side ordinate shows the distance from weld centerline, along the weld top surface, while the left side ordinate shows the strain rate. The results show that while increased welding speed caused a significant increase in strain rate, an opposite effect is produced by increasing power. The two trends show the same influence of heat input on the rate at which thermal strains are generated along the weld profile, starting from the weld surface to the weld root. The extents of thermal contraction that different HAZ locations experience during weld cooling differ due to the variation in the peak temperatures attained at these regions. The non-uniformity in material contraction constitutes the primary source of thermally induced strain. In a low heat input weld, which can be produced at high welding speed or low power, the rate at which the temperature changes from one location to another is high. The sharp temperature gradient results in a high cooling rate, which causes strain to be generated at a rapid rate, as reflected in the outputs of the model.

A careful study of the calculated results presented in Figures $5 \mathrm{a}, 5 \mathrm{~b}, 6 \mathrm{a}$ and $6 \mathrm{~b}$ shows another interesting behavior in terms of variation of the strain rate along the weld profile. A reverse in the strain rate behavior occurs at the neck region of the nail-shaped weld profiles. The strain rate initially decreases from the weld surface to the neck region, however, starting from the neck region, the rate increases towards the root of the weld. This behavior occurs both in laser and hybrid laser-arc welds. Reported experimental observations have showed that HAZ liquation cracks concentrate around the weld neck region (Nishimoto, et al., 2001; Idowu, et al., 2006). Moreover, the results show that the rate at which the strain rate increases with distance below the weld-neck region increases with decrease in heat input (Figures 5a, 5b, 6a and 6b). In concurrence with the numerical analysis results, reported cases exist in the literature where reduction in heat input was experimentally observed to have caused increased HAZ liquation cracking (Nishimoto, et al., 2001; Idowu, et al., 2006). This, thus, 
indicates that the strain rate gradient within the weld-neck region is an important mechanical driving factor that can influence the occurrence of HAZ liquation cracking.

The strain rate gradients within the neck region in laser and hybrid laser-arc welds were numerically calculated to compare the propensity to cracking during the two welding processes and under different welding conditions. As shown in Figures $7 \mathrm{a}$ and $7 \mathrm{~b}$, decrease in heat input, either by increasing welding speed or reducing power, produces increased strain rate gradient. Notably, the results show that there is a significant reduction in the strain rate gradient in hybrid laser-arc welds compared to in laser welds. This suggests that besides other technological advantages, reduction in propensity to HAZ cracking, through reduced thermally generated strain rate gradient, is another important benefit that can be achieved by the application of hybrid laser-arc welding compared to conventional laser welding, particularly, at low heat inputs. Limited experimental results on heat input dependence of cracking during hybrid laser-arc welding reported in the literature (Stelling. et al., 2005), provides credence to the theoretical analysis elucidated in this study.

\section{Summary and Conclusions}

1). A numerical model is developed to study the mechanical driving factor for HAZ liquation cracking during laser and hybrid laser-arc welding processes. The model is successfully verified with experimental weld geometry and secondary dendrite arm spacing within the weld fusion zone microstructure.

2). Numerically calculated results of variation of thermally induced strain rate with welding speed and power along the weld fusion boundary show a similar effect of heat input. A decrease in heat input produces an increase in the strain rate both during laser welding and hybrid laser-arc welding.

3). The model results reveal that increase in thermally generated strain rate starts at the weld-neck region and the rate at which it increases with distance along the weld profile becomes higher with decrease in heat input. This is consistent with reports in the literature where HAZ cracks have been experimentally observed to concentrate mainly in the weld-neck region and the magnitude of cracking increases with reduction in heat input.

4). The present study, thus, indicates that strain rate gradient that is thermally generated within the weld-neck region during weld cooling is an important mechanical driving factor that can influence the occurrence of HAZ liquation cracking.

5). Comparison of numerically computed strain rate gradient within the weld-neck region in laser and hybrid laser-arc welds shows a considerable reduction in the strain rate gradient in the hybrid laser-arc welds. This suggests that propensity to HAZ cracking can be reduced with the application of hybrid laser-arc welding technique compared to conventional laser welding, particularly, at low heat inputs.

\section{References}

Akbari D., \& Sattari-Far, I. (2009). Effect of the welding heat input on residual stresses in butt-welds of dissimilar pipe joints. International journal of pressure vessels and piping, 86, 769-776. htpp://dx.doi.org/10.1016/j.ijpvp.2009.07.005

ANSYS User's Manual Revision 13.0. http://www.ansys.com

Bonifaz, E. A., \& Richards, N. L. (2009). Modeling cast IN-738 superalloy gas tungsten arc welds. Acta materialia, 57, 1785-1794. htpp://dx.doi.org/ 10.1016/j.actamat.2008.12.022

Chang, K., \& Lee, C. (2009). Finite element analysis of the residual stresses in T-joint fillet welds made of similar and dissimilar steels. Int $J$ Adv Manuf Technol, 41, 250-258. htpp://dx.doi.org/10.1007/s00170-008-1487-4

Chen, Y. B., Lei, Z. L., Li, L. Q., \& Wu, L. (2006). Experimental study on welding characteristics of $\mathrm{CO}_{2}$ laser TIG hybrid welding process. Science and technology of welding and joining, 11(4), 403-411. http://dx.doi.org/10.1179/174329306X129535

Cho, W., Na, S., Cho, M., \& Lee, J. (2010). Numerical study of alloying element distribution in $\mathrm{CO}_{2}$ laser-GMA $\begin{array}{lllll}\text { hybrid welding. } & \text { Computational } & \text { Materials } & \text { Science, } & 49,\end{array}$ htpp://dx.doi.org/10.1016/j.commatsci.2010.06.025

Claus, Bagger, \& Flemming, O. Olsen. (2005). Review of laser hybrid welding. Journal of laser applications, Vol. 17(1), 2-13. htpp://dx.doi.org/10.2351/1.1848532

Dye, D., Hunziker, O., Roberts, S. M., \& Reed, R. C. (2001). Modeling of the mechanical effects induced by the Tungsten Inert-Gas welding of the IN718 superalloy. Metallurgical and materials transactions $A, 32 A$, 1713-1725. htpp://dx.doi.org/ 10.1007/s11661-001-0149-z 
Egbewande, A. T., Buckson, R. A., \& Ojo, O. A. (2010). Analysis of laser beam weldability of Inconel 738 superalloy. Materials characterization, 61, 569-574. htpp://dx.doi.org/ 10.1016/j.matchar.2010.02.016

Gao, Zhiguo, Wu, Yixiong, \& Huang, Jian. (2009). Analysis of weld pool dynamic during stationary laser-MIG hybrid welding. Int. J. Adv. Manuf. Technol, 44, 870-879. htpp://dx.doi.org/ 10.1007/s00170-008-1896-4

Goldak, J., Chakravarti, A., \& Bibby, M. (1984). A new finite element model for welding heat sources. Metallurgical Transactions B, 15B, 299-305. htpp://dx.doi.org/ 10.1007/BF02667333

Hee, S. B., Han, S. B., You, C. K., \& Sung, M. J. (2010). Analysis of residual stress on AH32 butt joint by hybrid $\mathrm{CO}_{2}$ laser-GMA welding. Computational materials science, 49, 217-221. htpp://dx.doi.org/10.1016/j.commatsci.2010.04.029

Hong, J., Park, J., Park, N., Eom, I., Kim, M, \& Kang, C. (2008). Microstructures and mechanical properties of Inconel 718 welds by $\mathrm{CO}_{2}$ laser welding. Journal of materials processing technology, 201, 515-520. htpp://dx.doi.org/ 10.1016/j.jmatprotec.2007.11.224

Hunziker, O., Dye, D., \& Reed, R. C. (2000). On the formation of a centerline grain boundary during fusion welding, Acta mater. 48, 4191-4201. htpp://dx.doi.org/10.1016/S1359-6454(00)00273-1

Idowu, O. A., Ojo, O. A., \& Chaturvedi, M. C. (2006). Effect of Weld Heat Input on Heat Affected Zone Microfissuring of a Newly Developed AllVac 718 Plus Superalloy. Materials Science and Engineering A, Vol. 454-455, 389-397. http://dx.doi.org/10.1016/j.msea.2006.11.054

Kong, F., \& Kovacevic, R. (2010). 3D finite element modeling of the thermally induced residual stress in the hybrid laser/arc welding of lap joint. Journal of Materials Processing Technology, 210, 941-950. htpp://dx.doi.org/ 10.1016/j.jmatprotec.2010.02.006

Lin, W., Lippold, J. C., \& Baeslack III, W. A. (1992). Analysis of weldability testing techniques for HAZ liquation cracking. Proceedings of International SAMPE Metals and Metals Processing Conference, October 2022, Toronto, Ontaria, Canada, 464-476.

Liu, F., Lin, X., Yang, G., Song, M., Chen, J., \& Huang, W. (2011). Microstructure and residual stress of laser rapid formed Inconel 718 nickel-base superalloy. Optics \& laser technology, 43, 208-213. htpp://dx.doi.org/10.1016/j.optlastec.2010.06.015

Luo, X., Shinozaki, K., Kuroki, H.,Yoshihara, S., Okumoto, Y., \& Shirai, M. (2002). Analysis of temperature and elevated temperature plastic strain distributions in laser welding HAZ study of laser weldability of Ni-base superalloy. Welding International, 16(5), 385-392. htpp://dx.doi.org/ 10.1080/09507110209549547

Nishimoto, K., Woo, I., \& Shirai, M. (2002). Analyses of temperature and strain distributions in laser welds study of the weldability of Inconel 718 cast alloy. Welding International, 16(4), 284-292. http://dx.doi.org/10.1080/09507110209549532

Nishimoto, K., Woo, I., Ogita, T., \& Shirai, M. (2001). Factors affecting HAZ cracking susceptibility of laser welds. Study of weldability of Inconel 718 cast alloy (4 ${ }^{\text {th }}$ report), Welding International 2001, 15(12), 965-972. 10. http://dx.doi.org/1080/09507110109549473

Pottlacher, G., Hosaeus, H., Kaschnitz, E., \& Seifter, A. (2009). Thermophysical properties of solid and liquid inconel 718 alloy. Scandinavian Journal of Metallurgy, 31, 161-168. htpp://dx.doi.org/10.1034/j.1600-0692.2002.310301.x

Quested, PN, \& McLean, M. (1980). Effect of variations in Temperature Gradient and Solidification rate on microstructure and creep behavior of IN738 LC. Solidification Technology in the Foundry and Cast House. The Metals Society Coventry England, 586-91

Rai, R., Roy, G. G., \& Roy, T. Deb. A computationally efficient model of convective heat transfer and solidification characteristics during keyhole mode laser welding. Journal of applied physics, 101, 054909, 1-11. http://dx.doi.org/10.1063/1.2537587

Ribic, B. D., Rai, R., Palmer, T. A., \& Deboy, T. (2008a). Arc-laser interactions and heat transfer and fluid flow in hybrid welding. Trends in welding research, proceedings of the $8^{\text {th }}$ international conference, 313-320.

Ribic, B., Palmer, T. A., \& DebRoy, T. (2009). Problems and issues in laser-arc hybrid welding. International materials reviews, 54 (4), 223-244. htpp://dx.doi.org/ 10.1179/174328009X411163

Ribic, B., Rai, R., \& DebRoy, T. (2008b). Numerical simulation of heat transfer and fluid flow in GTA/Laser hybrid welding. Science and technology of welding and joining, 13(8), 683-693. 
http://dx.doi.org/10.1179/136217108X356782

Stelling, K., Boellinghaus, Th., Lammers, M., \& Schobbert, H. (2005). Laser plasma power hybrid welding in vertical-up and vertical-down positions. Proceedings of the $7^{\text {th }}$ international conference on trends in welding research, Callaway gardens resort, Pine mountains, Georgia, USA, 2005,121-126.

Tsai, N., \& Eagar, T. (1985). Distribution of the Heat and Current Fluxes in Gas Tungsten Arcs. Metallurgical Transactions B, 16B, 841-846. htpp://dx.doi.org/ 10.1007/BF02667521

Ushio M., \& Wu, C.S. (1997). Mathematical modeling of three-dimensional heat and fluid flow in a moving gas metal arc weld pool. Metallurgical and materials transactions B, 28B, 509-516. htpp://dx.doi.org/ $10.1007 / \mathrm{s} 11663-997-0118-\mathrm{z}$

Wu, S., Zhao, H., Wang, Y., \& Zhang, X. (2004). A new heat source model in numerical simulation of high energy beam welding. Transactions of the china welding institution, 25(1), 91-94.

Table 1. Laser and Hybrid laser-arc Welding Parameters

\begin{tabular}{|c|c|c|c|c|c|c|}
\hline & $\begin{array}{c}\text { Laser power } \\
(\mathrm{kW})\end{array}$ & $\begin{array}{c}\text { Arc power } \\
(\mathrm{kW})\end{array}$ & $\begin{array}{c}\text { Welding speed } \\
(\mathrm{m} / \mathrm{min})\end{array}$ & $\begin{array}{c}\text { Time of laser } \\
\text { heating }(\mathrm{s})\end{array}$ & $\begin{array}{c}\text { Time of arc } \\
\text { heating }(\mathrm{s})\end{array}$ & $\begin{array}{c}\text { Time interval } \\
\text { for hybrid (s) }\end{array}$ \\
\hline Laser & 2 & - & 3 & 0.012 & - & - \\
\hline Laser & 4 & - & 3 & 0.012 & - & - \\
\hline Laser & 6 & - & 3 & 0.012 & - & - \\
\hline Laser & 4 & - & 2 & 0.018 & - & - \\
\hline Laser & 4 & - & 4 & 0.009 & - & - \\
\hline Laser & 4 & - & 6 & 0.006 & - & - \\
\hline Laser-GMA & 2 & 4.75 & 3 & 0.012 & 0.05 & 0.02 \\
\hline Laser-GMA & 4 & 4.75 & 3 & 0.012 & 0.05 & 0.02 \\
\hline Laser-GMA & 6 & 4.75 & 3 & 0.012 & 0.05 & 0.02 \\
\hline Laser-GMA & 4 & 4.75 & 2 & 0.018 & 0.075 & 0.03 \\
\hline Laser-GMA & 4 & 4.75 & 4 & 0.009 & 0.0375 & 0.015 \\
\hline Laser-GMA & 4 & 4.75 & 6 & 0.006 & 0.025 & 0.01 \\
\hline
\end{tabular}




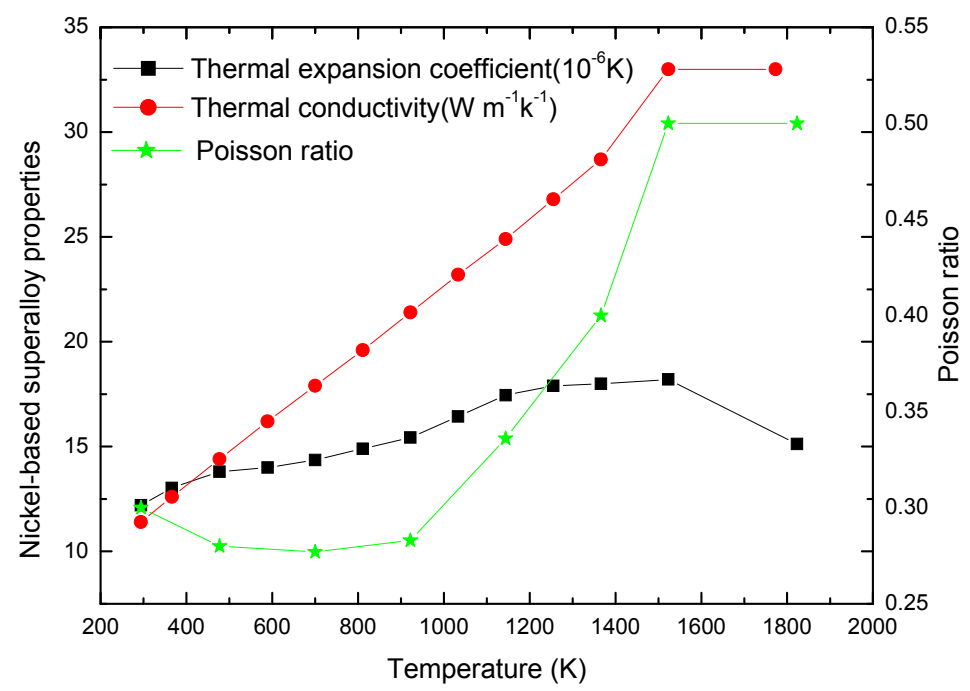

(a)

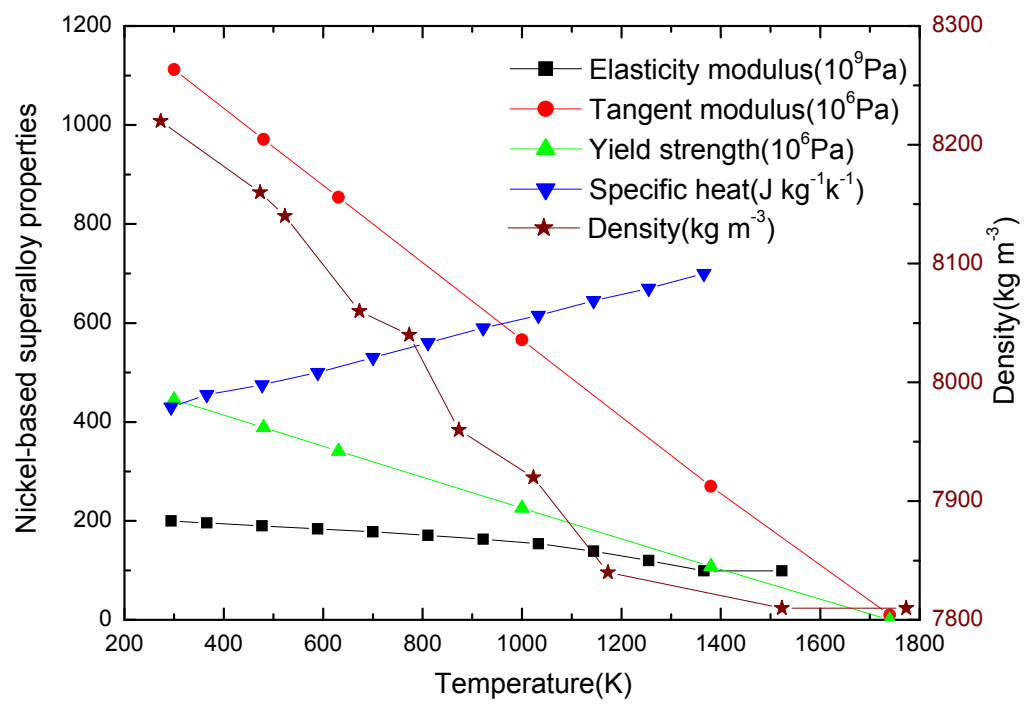

(b)

Figure 1 (a \& b). Physical and mechanical properties used in the numerical simulations (Luo, et al., 2002; Dye, et al., 2001; Bonifaz, et al., 2009; Pottlacher, et al., 2002) 


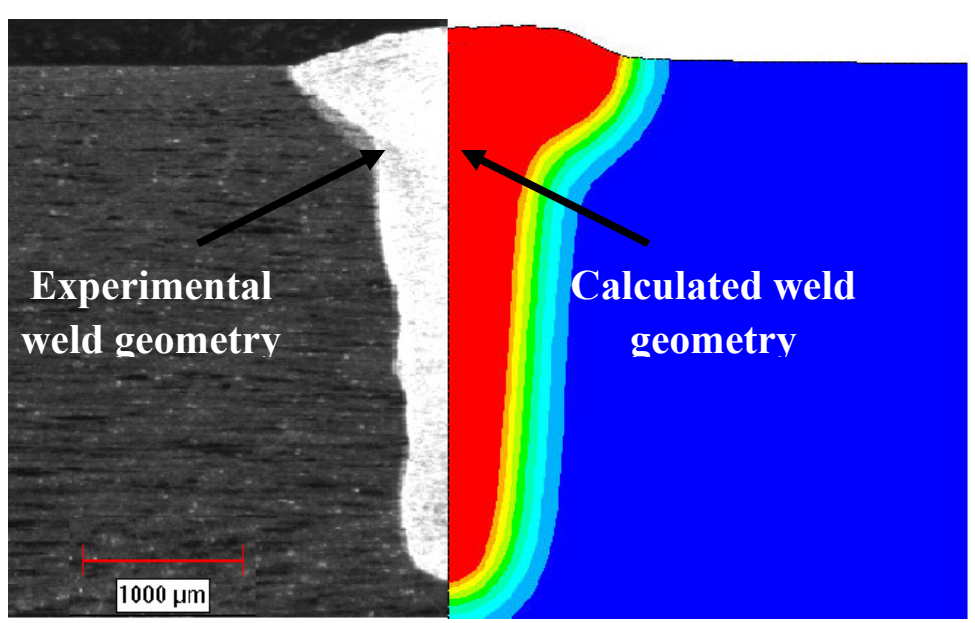

Figure 2. Comparison between model calculated and experimental laser weld geometry

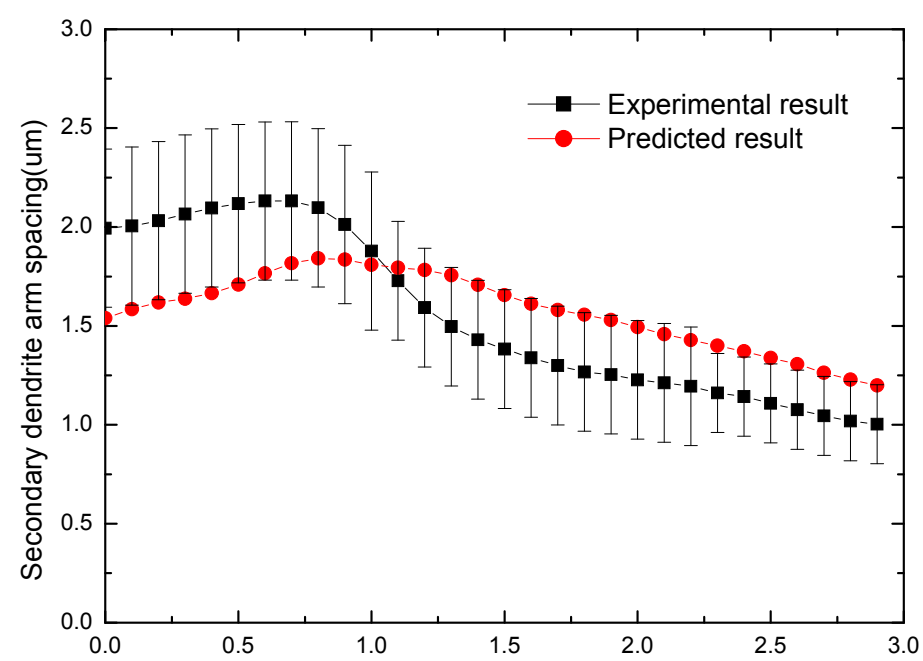

Distance from the surface to root of weld bead along fusion boundary $(\mathrm{mm})$

Figure 3. Variation of computed and experimental secondary dendrite arm spacing, $\lambda \mathrm{s}$, along the weld fusion boundary of a laser weld produced using a laser power of $4 \mathrm{~kW}$ and at a welding speed of $3 \mathrm{~m} / \mathrm{min}$ 


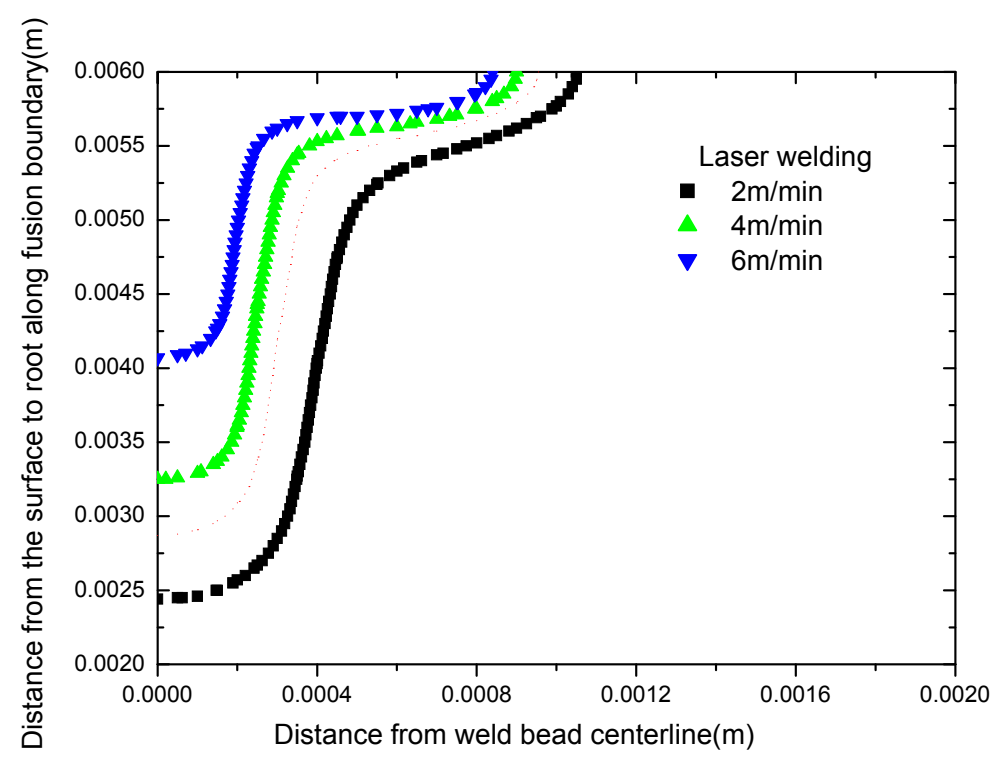

(a)

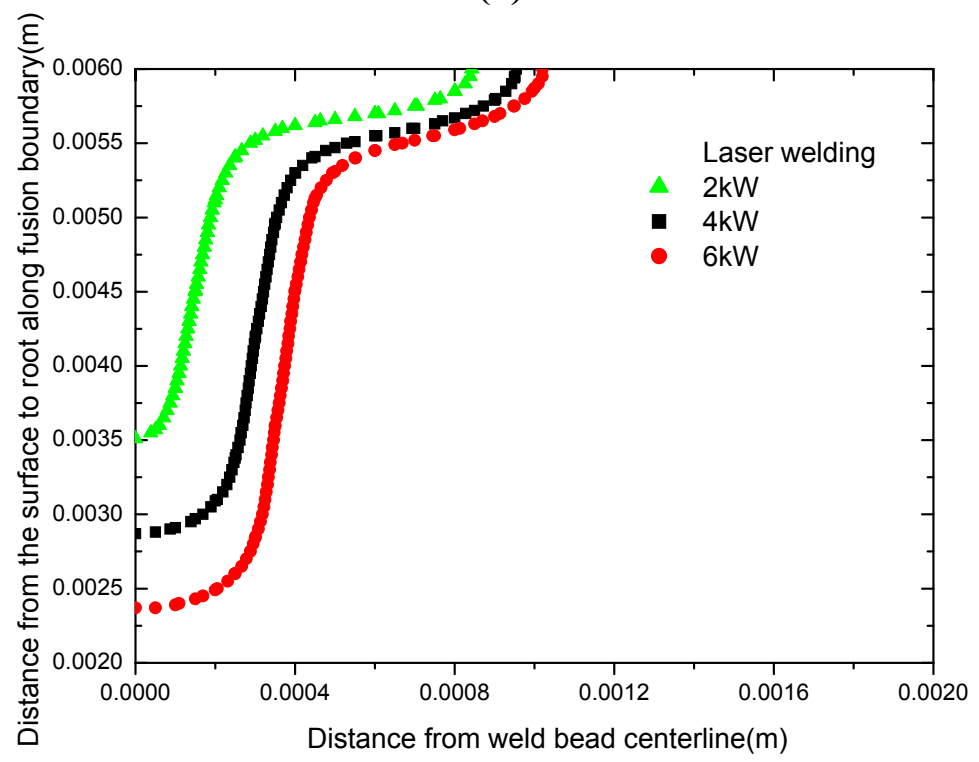

(b)

Figures 4 (a \& b). Model predicted laser weld profiles produced at (a) different values of welding speed and constant power and (b) different values of power and constant speed 


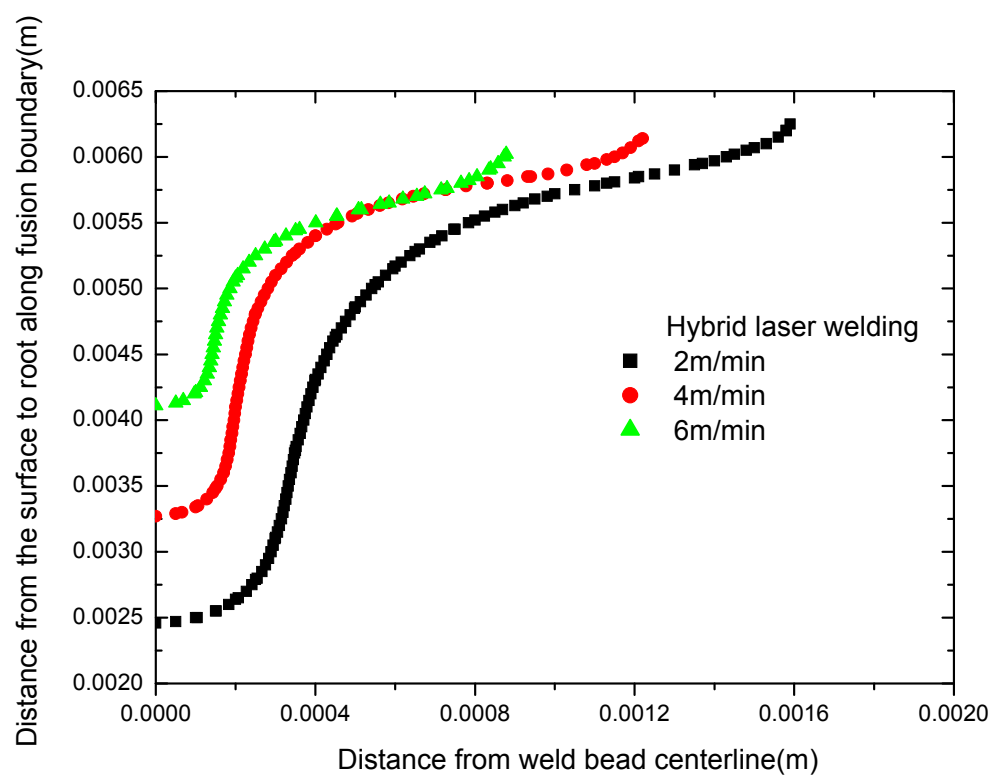

(c)

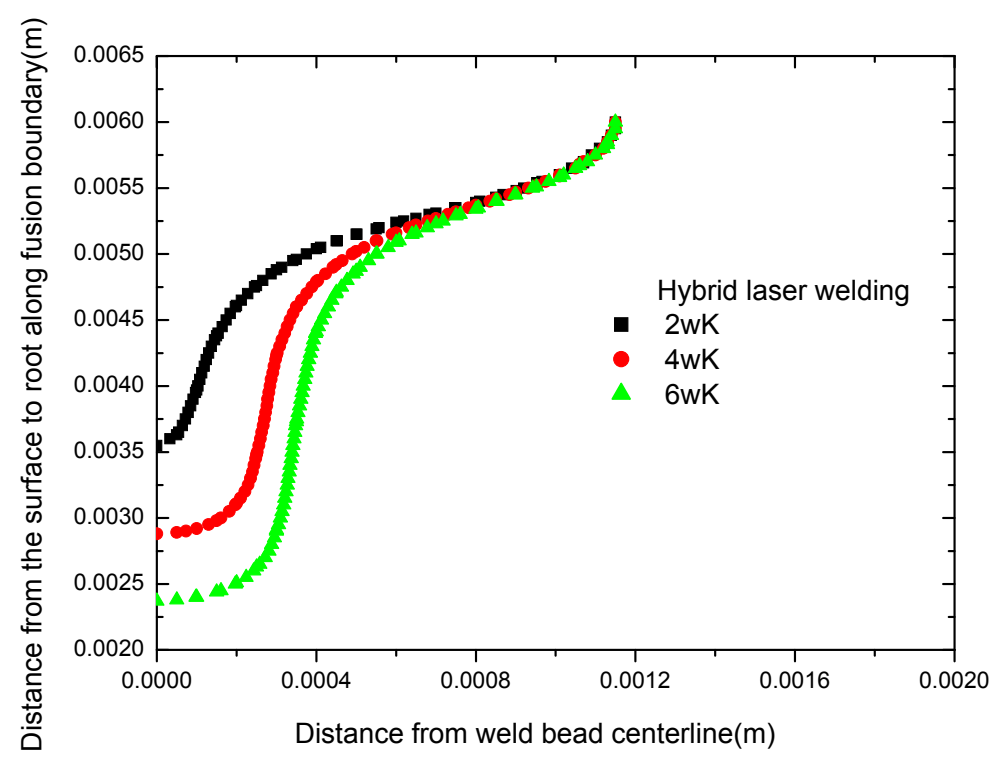

(d)

Figures 4 (c \& d). Model predicted hybrid laser-arc weld profiles produced at (c) different values of welding speed and constant power and (d) different values of power and constant speed 


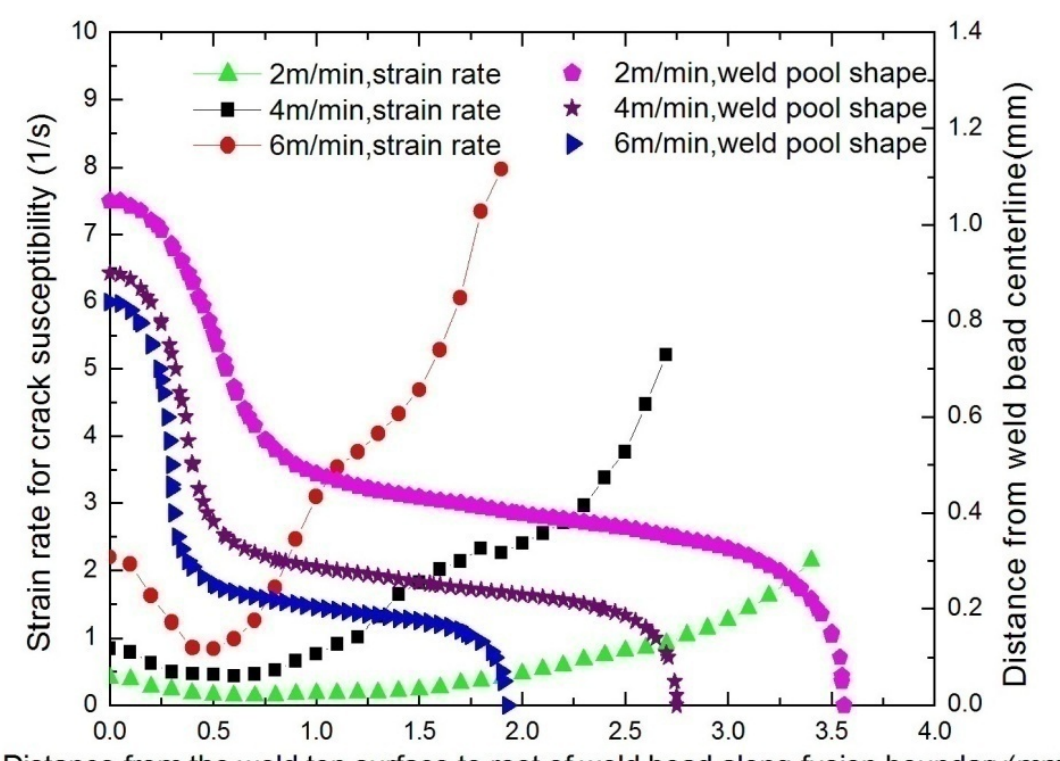

Distance from the weld top surface to root of weld bead along fusion boundary $(\mathrm{mm})$

(a)

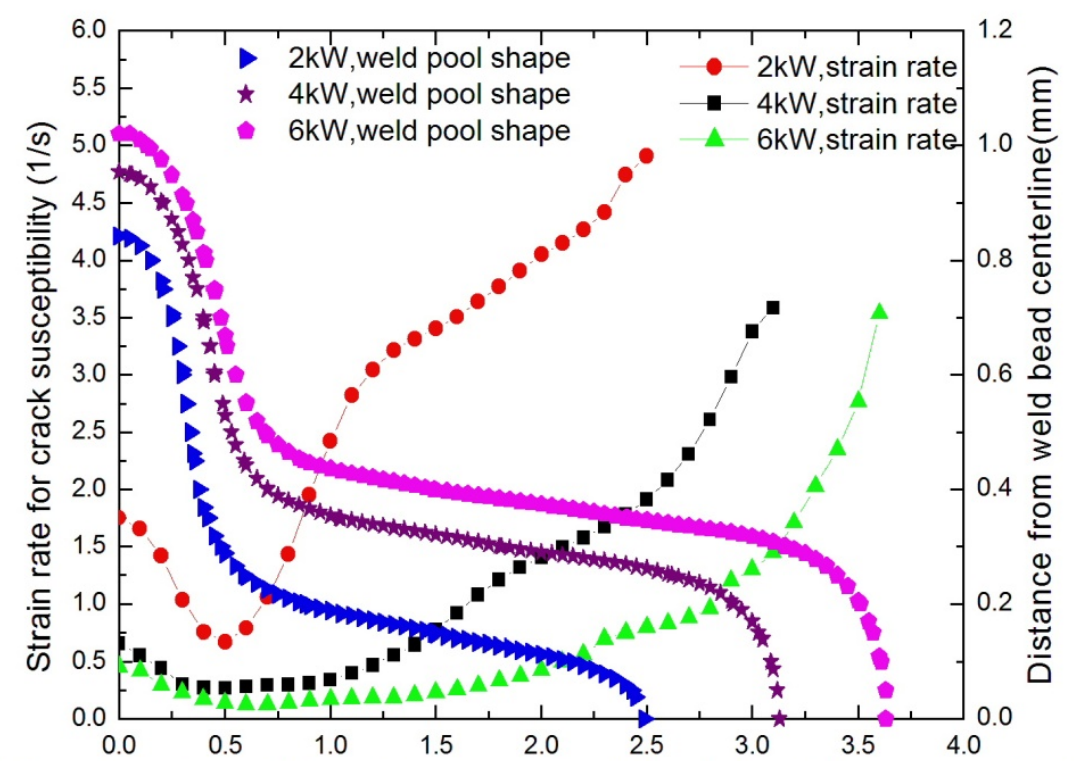

Distance from the weld top surface to root of weld bead along fusion boundary $(\mathrm{mm})$

(b)

Figures 5 (a \& b). Computed variation of strain rate along the fusion boundary of laser welds produced at (a) different values of welding speed and constant power and (b) different values of power and constant speed 


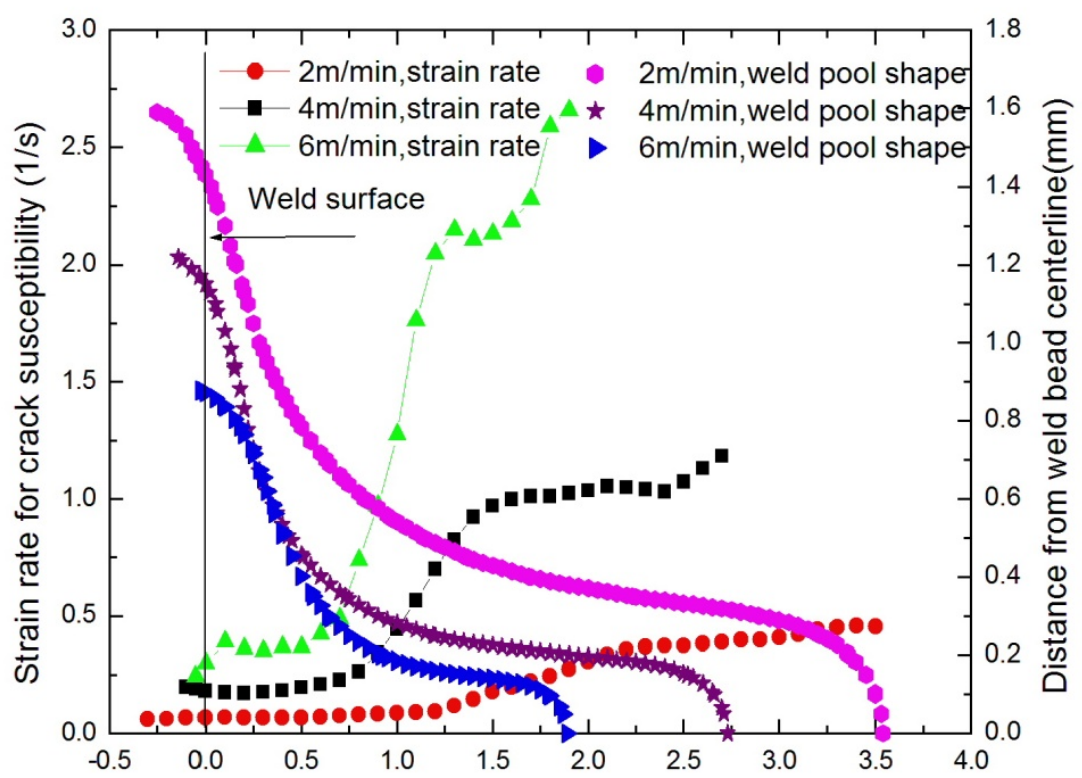

Distance from the weld top surface to root of weld bead along fusion boundary $(\mathrm{mm})$

(a)

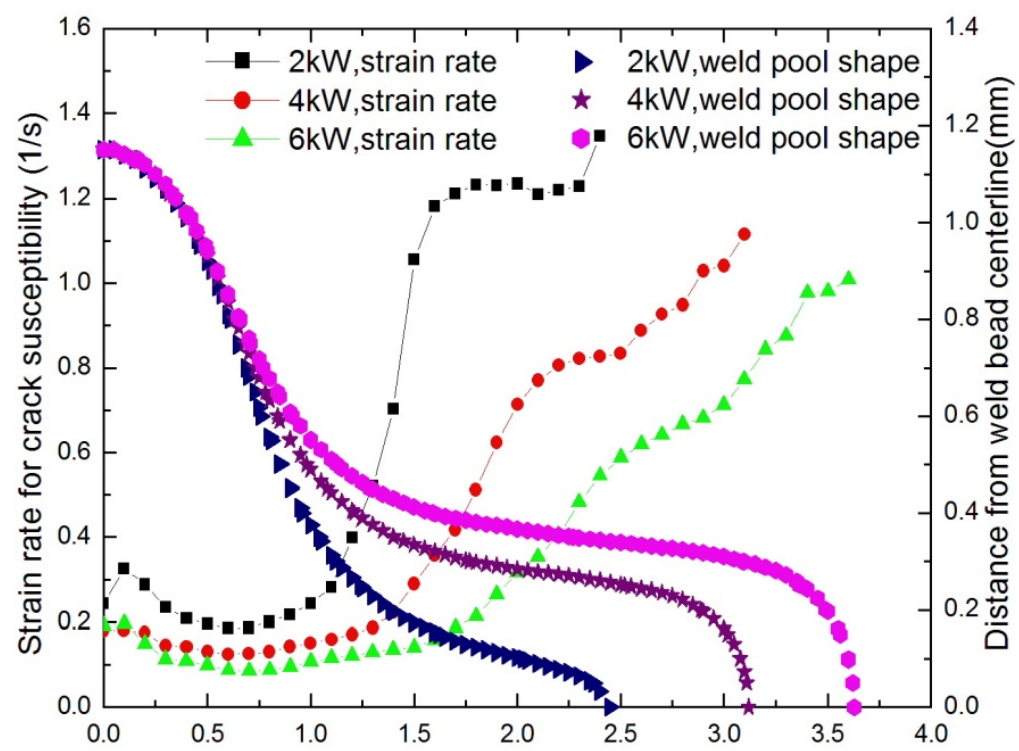

Distance from the weld top surface to root of weld bead along fusion boundary $(\mathrm{mm})$

(b)

Figures $6(\mathrm{a} \& \mathrm{~b})$. Computed variation of strain rate along the fusion boundary of hybrid laser welds produced at (a) different values of welding speed and constant power and (b) different values of power and constant speed 


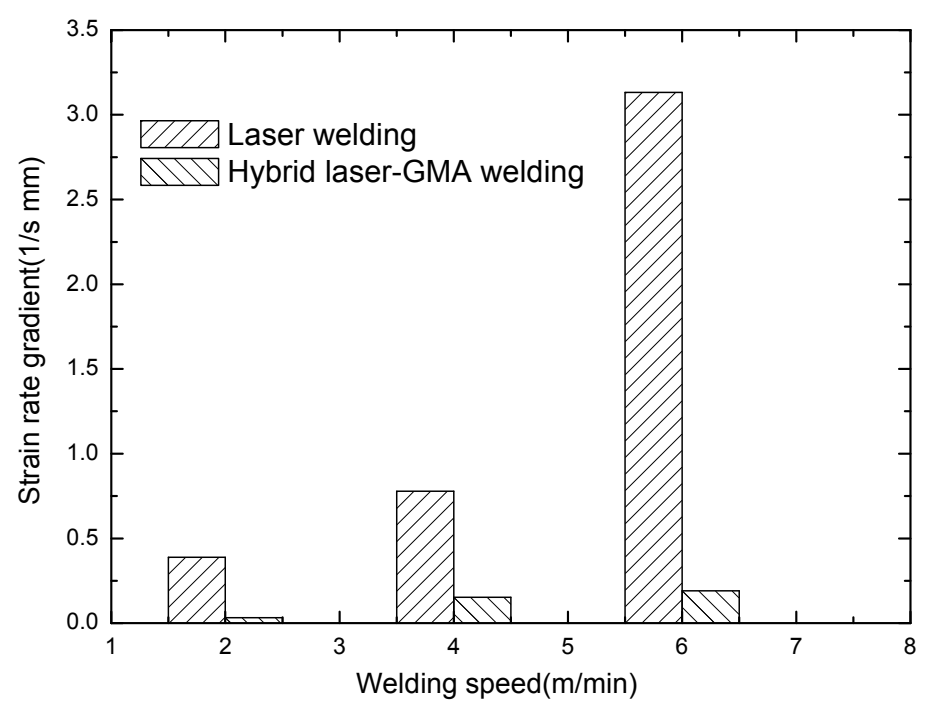

(a)

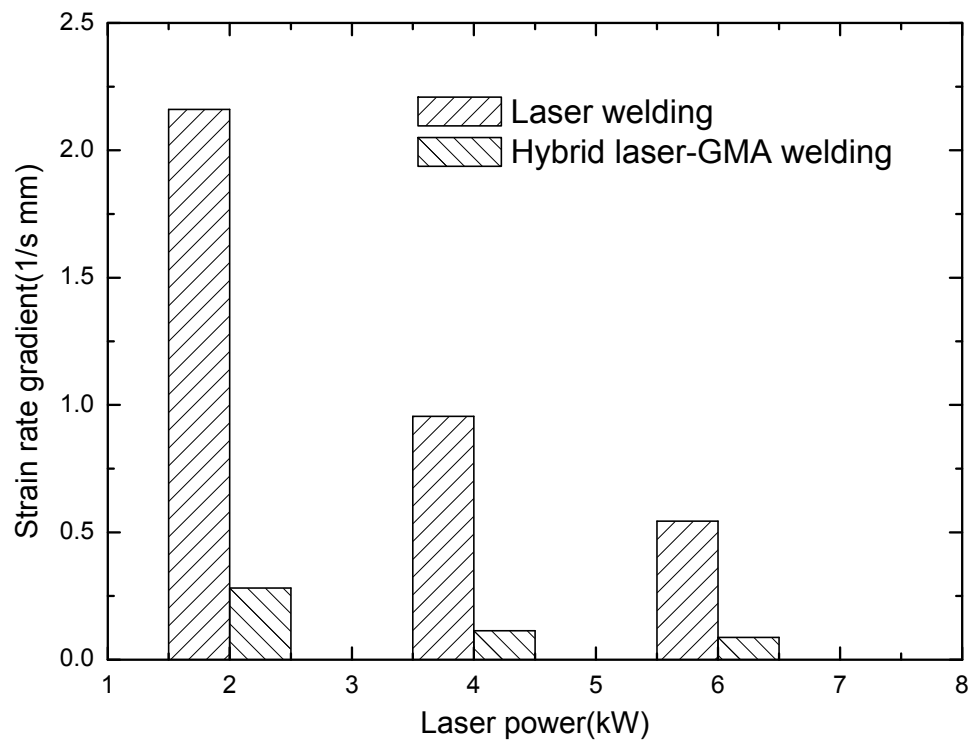

(b)

Figures $7(\mathrm{a} \& \mathrm{~b})$. Comparison of strain rate gradient in the neck region of laser welds and hybrid laser-arc welds produced at (a) different values of welding speed and constant power and (b) different values of power and constant speed 